\title{
Analysis of Induction Motor Performance Using Motor Current Signature Analysis Technique
}

\author{
Ramadoni Syahputra $^{* 1}$, Hedi Purwanto ${ }^{1}$, Rama Okta Wiyagi ${ }^{1}$, Muhamad Yusvin Mustar ${ }^{1}$, \\ Indah Soesanti ${ }^{2}$ \\ ${ }^{1}$ Department of Electrical Engineering, Faculty of Engineering, Universitas Muhammadiyah Yogyakarta \\ Jl. Lingkar Selatan, Tamantirto, Kasihan, Yogyakarta, Indonesia \\ ${ }^{2}$ Department of Electrical Engineering and Information Technology, Faculty of Engineering, \\ Universitas Gadjah Mada \\ Jl. Grafika 2, Kampus UGM, Yogyakarta, Indonesia \\ *Corresponding author, e-mail: ramadoni@umy.ac.id
}

\begin{abstract}
This paper discusses the analysis of the performance of an induction motor using the motor current signature analysis (MCSA) technique. Induction motor is a type of electric machine that is widely used in industry. One of the industries that utilize induction motors is a steam power plant (SPP). The role of induction motors is very vital in SPP operations. Therefore, it is necessary to monitor the performance, stability, and efficiency to anticipate disturbances that can cause damage or decrease the life of the induction motor. MCSA is a reliable technique that can be used to analyze damage to an induction motor. In this technique, the induction motor current signal is detected using a current transducer. The signal is then passed on to the signal conditioning and then into the data acquisition device. The critical signal data is analyzed with inadequate computer equipment. The results of this analysis determine the condition of the induction motor, whether it is normal or damaged. In this research, a case study was carried out at the Rembang steam power plant, Central Java, Indonesia. The analysis of several induction motors shows that most of them are in normal conditions and are still feasible to operate.
\end{abstract}

Keywords: Induction motor, steam power plant, damage, motor current signature analysis

\section{Introduction}

Induction motors are electromechanical equipment used in various industrial applications to convert electrical power into mechanical energy [1][3]. Induction motors are used in multiple fields such as in power generation, paper industry, oil fields and factories. Its use is primarily for pump drives, conveyors, press machines, elevators and many more [4]-[6]. Among the existing electric devices, induction motors are the most widely used because they are strong, sturdy, reasonably priced, reliable, easy maintenance, and high-power efficiency [7]-[8]. One type of industry that uses induction motors is a steam power plant.

Steam Power Plant (SPP) is the most widely used power plant in Indonesia because of its various advantages: it can be operated with multiple fuel types. It can be built with varying capacities, employed with various loading operations, and continuous process and relative service lifelong. SPP coal has five main components: a boiler or steam generator, a steam turbine, a pump, a condenser, and a generator. These components work in conjunction to produce electrical energy. The boiler is the main component that functions as a generator of steam used to turn the turbine. Boilers make steam by burning coal in a combustion room or furnace around the combustion room, and there are water or steam pipes.

One of the SPPs that operates using coal as fuel in Indonesia is PT PJB UBJ O\&M SPP Rembang, owned by PT. PLN (Persero), which is operated by 
PT. PJB UBJ O\&M (Java-Bali Generation of Operations and Maintenance Services Business Unit) has a capacity of $2 \times 315$ MW.

SPP Rembang has three central systems: the Boiler System, Turbine System, and Balance of Plant System. The system works in conjunction to produce electrical energy. To maintain the reliability of the system that works at SPP Rembang, predictive maintenance is carried out. Predictive maintenance is maintenance carried out based on monitoring and analyzing the operating conditions of the power plant to detect abnormalities early. One of the methods used in predictive maintenance at SPP Rembang uses the Motor Current Signature Analysis (MCSA) method to detect unbalanced currents and damage to the three-phase induction motor, which is part of the equipment SPP Rembang.

The purpose of this study was to analyze the damage to the rotor bar and unbalanced currents in a 3-phase induction motor using the motor current signature analysis (MCSA) technique. This analysis is an anticipatory measure if an abnormality in the induction motor can be detected as early as possible to take corrective or replacement action [9].

\section{Literature Study}

\section{II.1 Induction Motor}

Due to the natural aging process and various other factors associated with the operating pattern of the induction motor, damage to the induction motor can occur. Electrical and mechanical stress are examples of damage due to operating patterns [10]. Mechanical stress occurs due to overloads and sudden load changes resulting in bearing damage and broken rotor bars. Electrical stress is usually associated with a voltage source problem. For example, an induction motor sourced from an AC drive tends to experience electrical stress due to the high frequency of the stator current component, over-voltage due to the length of the cable between the motor and the AC drive due to the reflection of the transient voltage wave. This electrical stress can cause a short circuit of the stator winding which means total damage to the induction motor [11]-[12].

If the damage to the induction motor is not detected at the initial stage, it will cause severe damage with various types of damage. Undetected motor damage can result in a shutdown of the production process, which of course causes loss of productive time due to lengthy machine repairs, high maintenance costs due to the large number of components that must be replaced, and loss of production raw materials that should be processed but must be wasted because the machine stops operate [13].

An induction motor consists of a non-rotating part (stator) and a rotating element (rotor), as shown in Fig. 1. The stator consists of dynamo blocks that are insulated on one side and have a thickness of 0.35-0. $5 \mathrm{~mm}$, arranged into a block package in the shape of a bracelet. Inside is equipped with grooves. There is a difference between an asynchronous motor with a nest winding (a nest rotor or short circuit rotor) and a drag ring with a three-phase winding in this groove. Or, from the other side, the iron core of the stator and rotor are made of layers (enamel) of silicon steel 0.35 - $0.5 \mathrm{~mm}$ thick, neatly arranged, each electrically insulated and fastened at the ends.

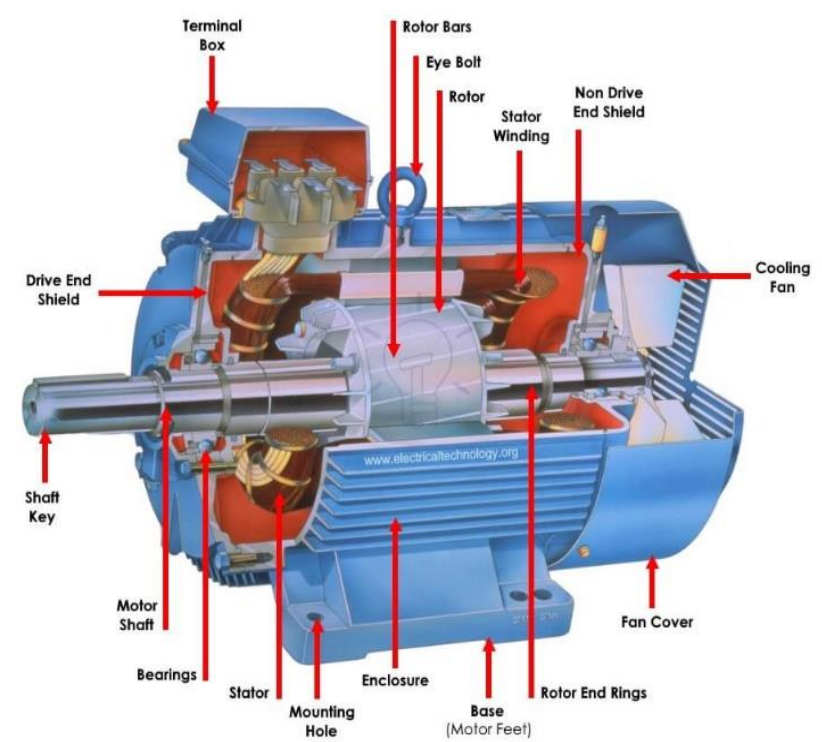

Fig. 1. Typical induction motor construction

Lamely iron core of the stator and rotor of the motor part with the diameter of the motor part, with the outer diameter of the stator more than $1 \mathrm{~m}$. For motors with a larger diameter, the iron core lamellas are the core arc segments joined together into a loop. The air gap between the stator and rotor in small motors is $0.25-0.75 \mathrm{~mm}$. In large motors, it is up to $10 \mathrm{~mm}$. This large air gap provides possible stretching of the axes because of transverse loading on the axes or their joints. Pull-on the ribbon (belt) or the load that depends on it will cause the motor axis to curve.

The stator iron core and the motor rotor windings 
are not synchronous with the stator and engine stator windings simultaneously. This similarity can be shown that the asynchronous engine rotor, which is installed following the engine stator, will not simultaneously work correctly.

In the stator, several slots are the place for the wire (conductor) of the three coils, each of which has a different phase and receives current from each of these phases, called the stator coil. The stator consists of iron plates arranged the same size as the rotor, and on the inside, it has many grooves coiled with insulated copper wire. If the stator coil gets a threephase current supply, the coil will generate a rotating magnetic flux. The rotating magnetic change on the stator coil causes the rotor to rotate due to magnetic induction with the rotating speed of the rotor in sync with the stator rotating speed. The construction of the induction motor stator consists of several parts, namely the motor body (axle), the core of the magnetic poles and the coils of magnetic reinforcement, and the slip ring.

Based on Faraday's law of magnetic impact, the rotating field, which is relatively a magnetic field moving towards the conductor of the rotor, will shake off the electromotive force (emf). The frequency of this induced emf is the same as the grid frequency. The magnitude of this induced emf is directly proportional to the relative speed between the rotating field and the conductor of the rotor. The conductors in the rotor that form a closed circuit are driving for rotor currents and are in line with the applicable law, namely Lenz's law. The direction is against the impact flux. In this case, the rotor current is generated because of the difference in speed between the flux of the stator rotating field and the stationary conductor. The rotor will rotate in the same direction as the direction of the rotating stator field to reduce the speed difference above. If the rotor is loaded, the rotation will decrease so that there is a difference in rotational speed between rotor and stator. This difference in rotation speed is called slip.

\section{II.2. Motor Current Signature Analysis Technique}

MCSA is a monitoring method for three-phase induction motors by analyzing the current passing through the stator winding [14]. The MCSA procedure is to take current from the winding stator using a sensor from the current transformer in the MCSA probe then the data is analyzed and stored in CSi 2130 in the form of a signal, if a disturbance occurs then it is analyzed again using AMS Healthy Machinery software [15]-[16].

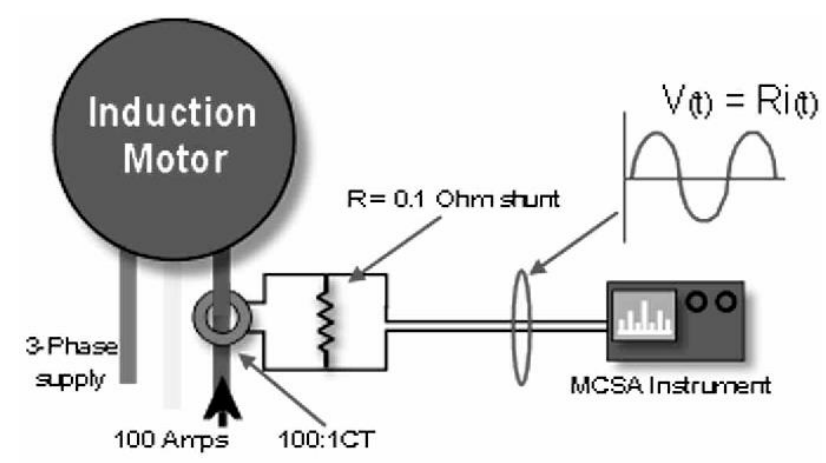

Fig. 2. MCSA procedure

In Fig. 2, it can be seen that the procedure in MCSA is taking current from the winding stator using sensors from the current transformer inside the MCSA probe, then the data is analyzed and stored temporarily in CSi 2130, if there is a disturbance, the data will be analyzed using AMS Healthy Machinery software. Fig. 3 shows a chart of the MCSA data collection process when monitoring the induction motor.

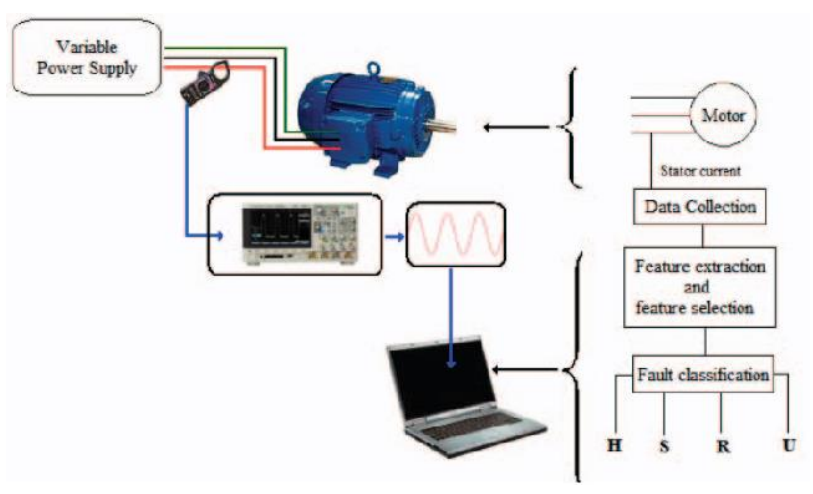

Fig. 3. MCSA data collection process when monitoring the induction motor

Motor current signature analysis (MCSA) is a system for researching or dynamic trends, provided by an electric power system. Analysis according to the MCSA results will assist technicians in identifying [17]:

1. Health incoming winding

2. Health of the stator windings

3. Rotor health

4. Air gap static and dynamic eccentricity

5. Health of the coupling, including the belt system and gear system

6. Load

7. System load and efficiency

8. Bearing health 
A motor current signal is ideally a perfect sinusoidal wave at $50 \mathrm{~Hz}$. With pictures, we can represent the current in terms of time as well as frequency. Fig. 4 shows the first image (Fig. 4.a), which is the relationship between current and time, while the second image (Fig. 4.b) shows the relationship between current and frequency. Fig. 4 shows a $50 \mathrm{~Hz}$ signal in the time and frequency domains.

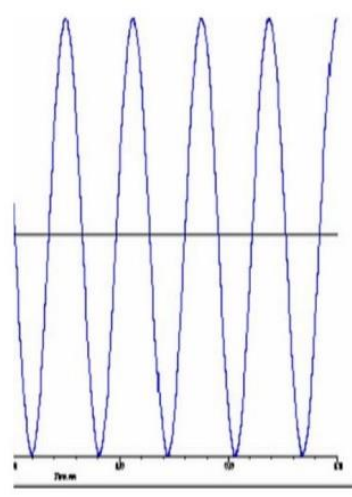

(a)

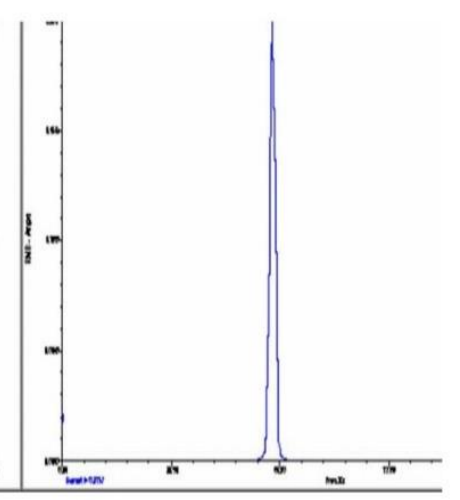

(b)
Fig. 4. A $50 \mathrm{~Hz}$ signal in the time and frequency domains

The amplitude of the peak frequency is equal to the RMS amplitude of the sine wave. It is theoretical that in the absence of a harmonic, we can see that there is only one peak in the frequency spectrum. Current conversion from time to frequency area is achieved using the Fast Fourier Transform (FFT) algorithm [18]-[19].

As long as the motor is operating, many harmonic signals will be present in the motor. A signal will show many peaks that include the line frequency and harmonics. This is what is known as the motor's current signature. This harmonic study after the influence of amplification and signal conditions will allow the identification of various faults in the motor.

One of the main features of MCSA is the rotor analysis [20]. Broken rotor bar, static eccentricity and dynamic eccentricity are the three basic types of motor issues that can be analyzed using the MCSA method. Broken rotor bars are usually found when the frequency sidebands slip around the frequency line. The standard rule from experience is that errors are detected when these sidebands are found to exceed $-35 \mathrm{~dB}$ or what is known as " $35 \mathrm{~dB}$ down".

Static eccentricity can be found in the high frequency spectrum. Static eccentricity occurs when the center frequency does not reach the peak in the spectrum but is arranged as the product of the product of the running frequency (RF) and the number of rotor bars (RB) of an induction motor. Dynamic eccentricity is different from static eccentricity. In dynamic eccentricity, there will also be a running speed sideband around the static eccentricity sideband from the base frequency.

\section{Methodology}

PT PJB UBJ O\&M Steam Power Plant (SPP) Rembang is located in Leran and Trahan villages, Sluke District, Rembang Regency. The SPP location is about $137 \mathrm{~km}$ from the city of Semarang to the east and is on the north side of the main road on the north coast of east side of Central Java. Fig. 5 shows the location of this study in google maps.

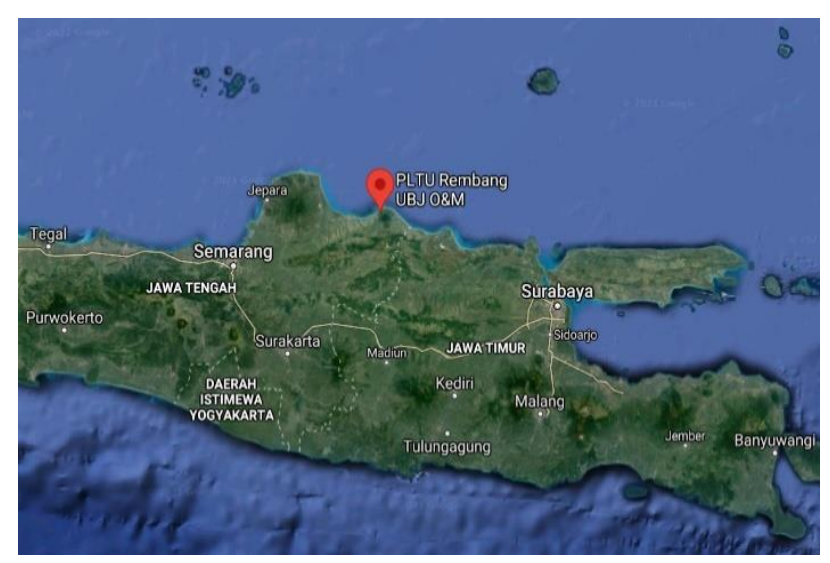

Fig. 5. Location of this study in google maps

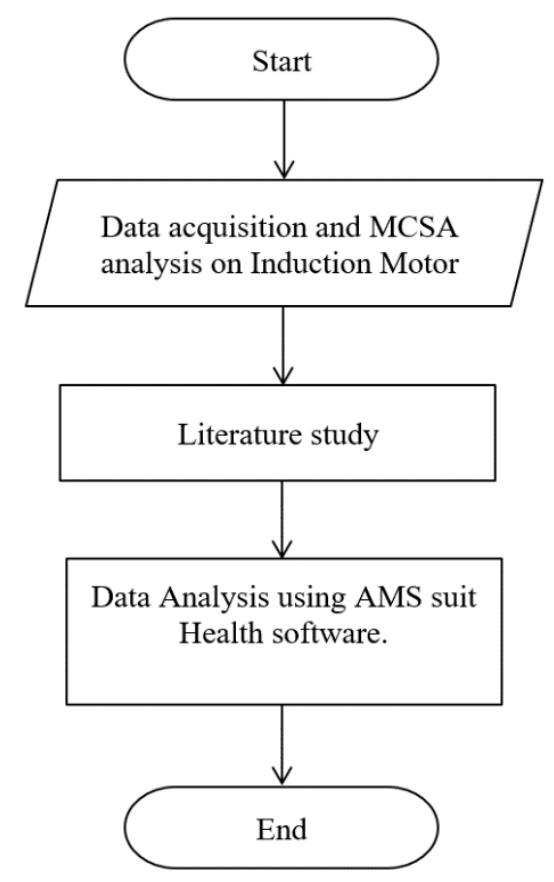

Fig. 6. Flowchart of the research step 
The steps of this research are shown in Fig. 6. The initial step of the research was the analysis of the motor. This step is the initial stage carried out in data collection using the MCSA tool on the three-phase induction motor used in PT PJB UBJ O\&M SPP Rembang. The next step is a literature review. Literature review is carried out to find information about theories, methods, and concepts relevant to the problem. Based on this information, it can be used as a reference in solving problems. Literature study is carried out by looking for information and references in the form of textbooks, information from the internet and other sources. The final and most important step is data analysis using AMS suit health machinery software. From the analysis using AMS Suite Health Machinery software, an induction motor diagnosis will be obtained which will be analyzed later. The data to be analyzed is the unbalance current output data and the damage to the rotor bar whether the motor is in good condition or not.

\section{Results and Discussion}

\section{IV.1 Post-Fault Induction Motor Testing Using MCSA}

This research originated from the problems that occurred in PT UBJ O\&M Steam Power Plant (SPP) Rembang. One of the three-phase induction motor units at SPP Rembang had an operation failure. The induction motor unit functions as a driver for the motorized lube oil bfpt pump, as shown in Fig. 7.

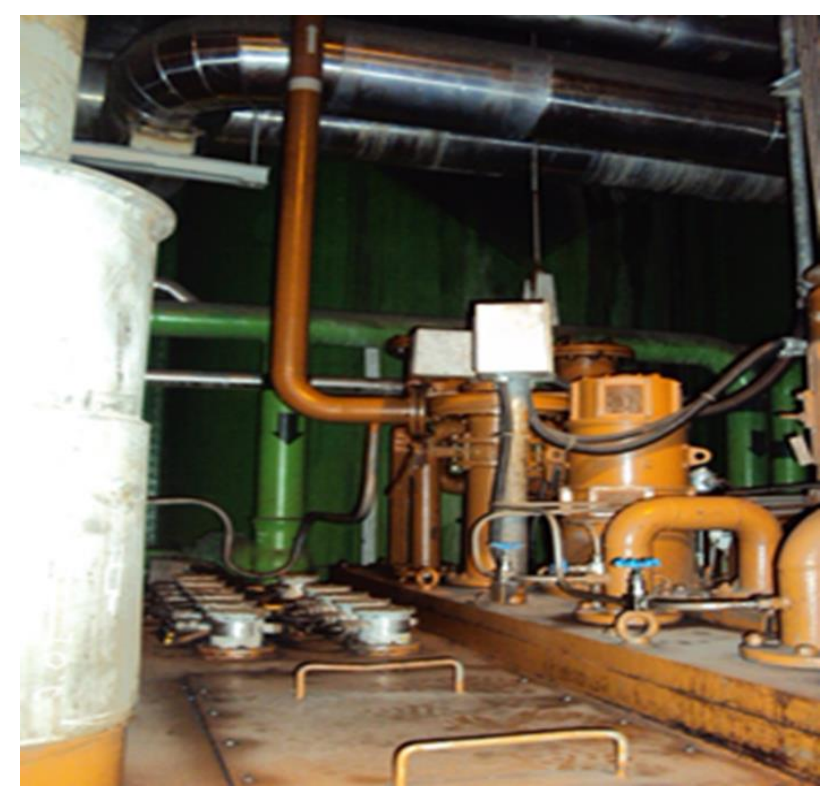

Fig. 7. Motor lube oil bfpt pump in SPP Rembang
The specifications of the three-phase induction motor used in the lube oil bfpt pump motor are shown in Table 1 . The motor power capacity is $18.5 \mathrm{~kW}$, the working voltage is 400 volts at a nominal current of 33.9 amperes. The nominal speed of the motor is $2930 \mathrm{rpm}$, and the system frequency is $50 \mathrm{~Hz}$.

TABLE I

SPECIFICATION OF INDUCTION MOTOR IN THIS RESEARCH

\begin{tabular}{lc}
\hline \multicolumn{1}{c}{ Parameters } & Quantities and Units \\
\hline Power capacity & $18.5 \mathrm{~kW}$ \\
Nominal voltage & 400 volts \\
Normal current & 33.9 ampere \\
Rotation & $2930 \mathrm{rpm}$ \\
Frequency & $50 \mathrm{~Hz}$ \\
\hline
\end{tabular}

The analysis of the rotor bar was carried out to determine the level of damage to the rotor bar. The results of the analysis using the MCSA tool display the current spectrum in the frequency domain, as shown in Fig. 8.

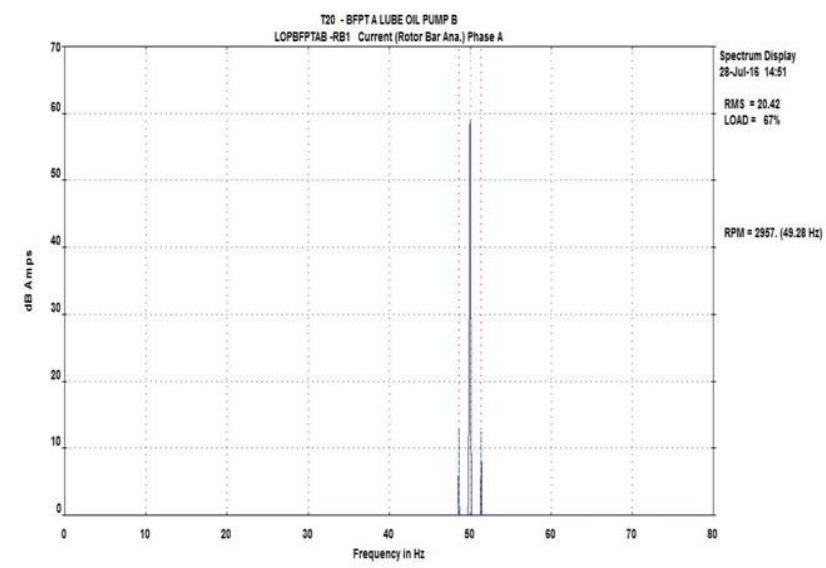

Fig. 8. Current spectrum in the frequency domain from MCSA

To analyze the condition of the rotor bar on an induction motor, it is necessary to first calculate the frequency of running speed of the induction motor. Based on the operation data of the induction motor, it is found that the motor rotation is $2957 \mathrm{rpm}$. Thus, the frequency of running speed of the induction motor is $49.28 \mathrm{~Hz}$. After knowing the running speed frequency of $49.26 \mathrm{~Hz}$, to find out the value of the synchronous speed frequency, which is according to the nominal frequency of $50 \mathrm{~Hz}$. By calculating the running speed and the synchronous speed or slip frequency, the side band frequencies that occur around the line frequency can be determined. The 
sideband frequency of the MCSA analysis was 1.44 $\mathrm{Hz}$. Based on the sideband frequency value of 1.44 $\mathrm{Hz}$, it can be interpreted that the sideband that appears around the frequency line is $48.56 \mathrm{~Hz}$ and $51.44 \mathrm{~Hz}$. The value of the sideband frequency that appears between the line frequency can be seen in Fig. 9.

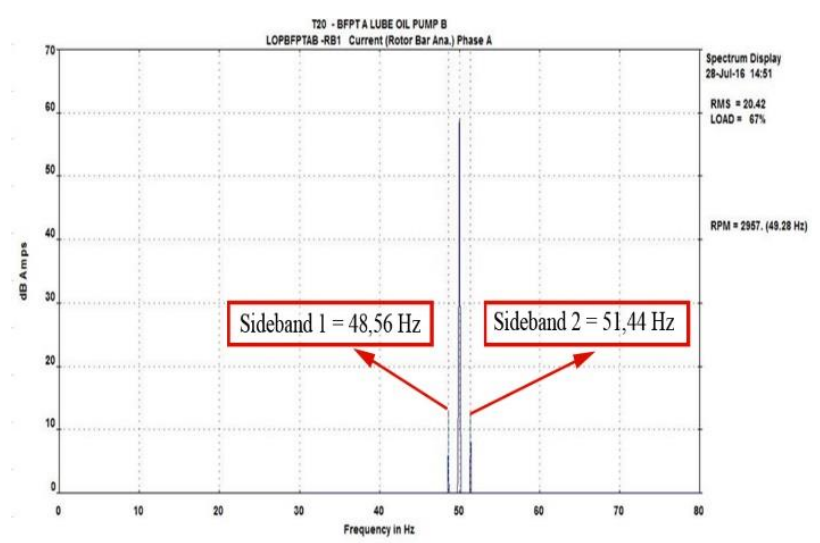

Fig. 9. Sideband frequency that appears between the line frequency

Furthermore, to determine the indication of the damage to the rotor bar of an induction motor, it can be seen the amount of decrease that occurs between the line frequency and the side band frequency. Determination of the presence or absence of rotor damage must be in accordance with the standards of EASA as shown in Fig. 10. Fig. 10 shows that if the sideband frequency that occurs is $-17.32 \mathrm{~Hz}$ at the peak of the line frequency of $50 \mathrm{~Hz}$, or if using the Fast Fourier Transform (FFT) algorithm can be converted to a value of $-40 \mathrm{~dB}$, it can be determined that the motor is identified with a damage to the rotor bar. By comparing the results of the analysis at low frequency with the standard from EASA, it can be seen that the degradation on the spectrum curve is $44.55 \mathrm{~dB}$, so it can be said that the motor lube oil bfpt pump identifies damage to the rotor bar.

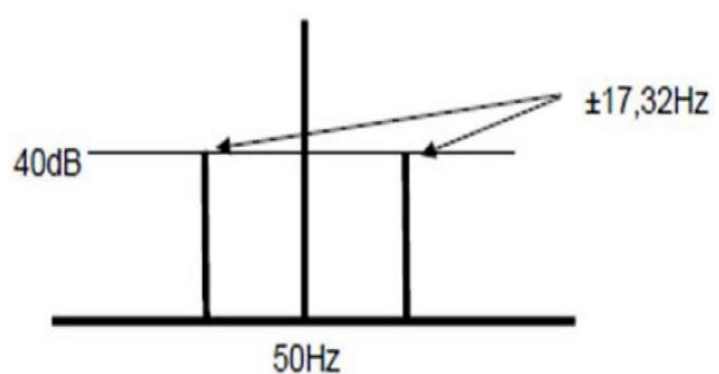

Fig. 10. Standards of EASA for rotor bar of induction motor diagnosis
The next analysis is the current imbalance in each phase of the induction motor. The measurement results show that when there is a disturbance in the induction motor, the current in the R phase is 20.97 amperes, the $\mathrm{S}$ phase is 21.33 amperes, and the $\mathrm{T}$ phase is 20.05 amperes. From the three values of the phase currents above, it can be seen that the flow between the phases is not balanced, so that the data must be further analyzed using AMS Suite Health Machinery software. Data analyzed and processed into the AMS Suite Health Machinery software is the result of measurements with CSi 2130 which shows the flow is not balanced between the phases. If the MCSA measurement results with CSi 2130 produce normal conditions, the data will not be processed and analyzed further, but monitoring is still carried out according to a periodic checking schedule.

The results of the analysis of the percentage of unbalanced current from the induction motor on the motor lube oil bfpt pump when a disturbance occurs which is analyzed using AMS Health Machinery software is shown in Fig. 11.

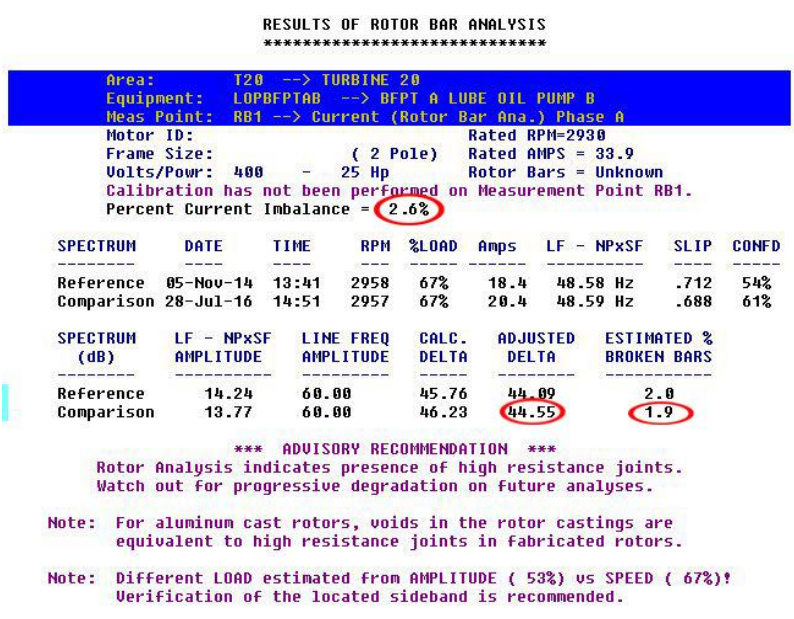

Fig. 11. Results of the analysis of the percentage of unbalanced current of the induction motor when a disturbance occurs using AMS Health Machinery software

From the AMS Suite Health Machinery analysis results obtained the percentage of current unbalance data is $2.6 \%$, the adjusted delta is $44.55 \mathrm{~dB}$, and the percentage of damage to the rotor bar is $1.9 \%$.

From the results of experimental data and analysis results obtained percent unbalance flow of $2.6 \%$. The induction motor manufacturer has determined the allowable level for the percent of unbalanced current not to exceed $10 \%$. The imbalance of the current between the phases in a three-phase induction motor 
can affect the value of the voltage and resistance on the motor. With the greater the current value, the greater the voltage and the smaller the resistance and vice versa. If any of the $\mathrm{R}, \mathrm{S}$, and $\mathrm{T}$ phases are over current it can cause over voltage, if this happens it will cause overheating. If there is a small current in one of the phases, the possibility of resistance will be even greater, and this can also cause overheating. So that from condition-based maintenance (CBM) provides recommendations for checking the termination related to the condition of the motor temperature. In addition, the size of the resistance also affects the current and voltage so that the CBM provides a recommendation to check the winding resistance.

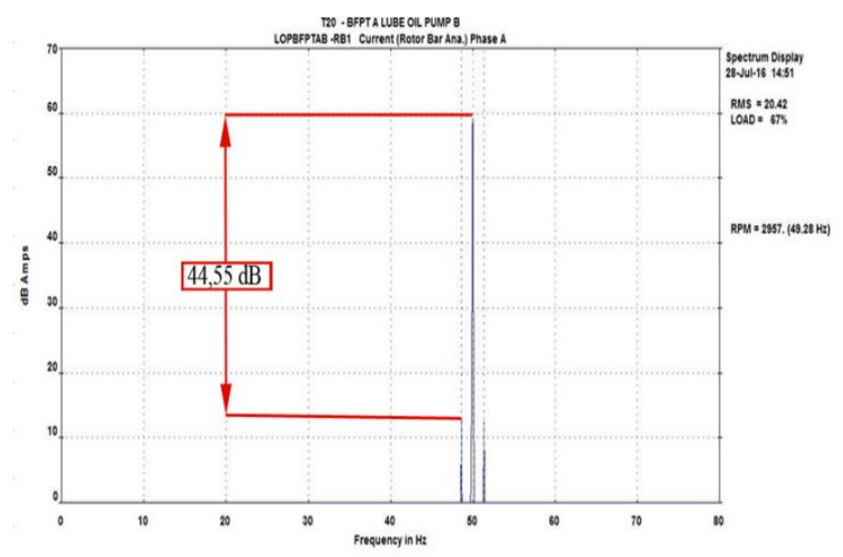

Fig. 12. A signal that indicates a damage to the rotor bar of the induction motor

The estimate for broken rotor bars is $1.9 \%$. If the estimation is getting bigger, the condition of the rotor bar is getting worse. The condition of the rotor bar damage can be seen as shown in Fig. 12. The signal gain $(\Delta \mathrm{dB})$ is $44.55 \mathrm{~dB}$. This value is obtained from the difference between the peak frequency and the lower side band. In accordance with the standards of the Electrical Apparatus Service Association (EASA), the data shows the motor is in "marginal condition".

\section{IV.2 Post-Reparation Induction Motor Testing Using MCSA}

Based on the test results which state that the induction motor is in "marginal condition", an induction motor is repaired. Actually, at this marginal condition the induction motor can still be operated. However, to prevent more fatal damage during operation, it is better to do repairs. This motor repair can also extend the service life of the induction motor.

After the repair is complete, before using the induction motor, the test is carried out using MCSA. The analysis of the rotor bar was carried out to determine the level of damage to the rotor bar. The results of the analysis using the MCSA tool display the current spectrum in the frequency domain, as shown in Fig. 13.

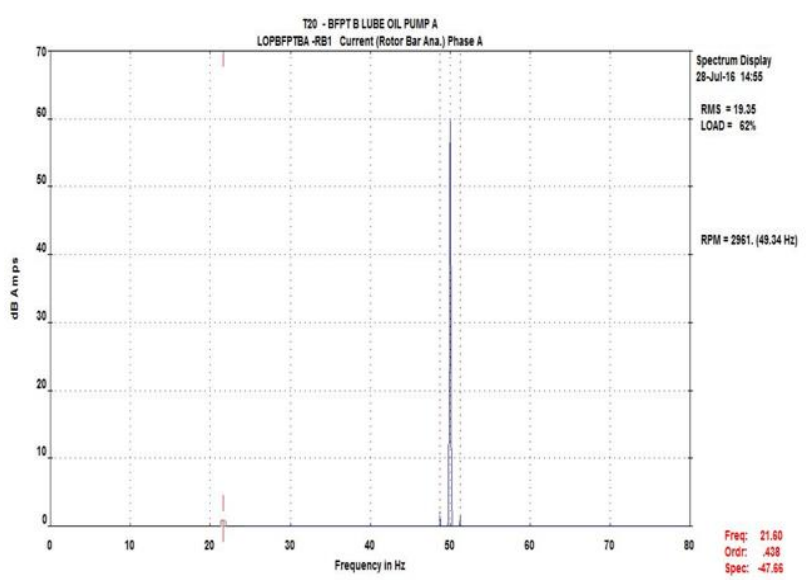

Fig. 13. Current spectrum in the frequency domain from MCSA

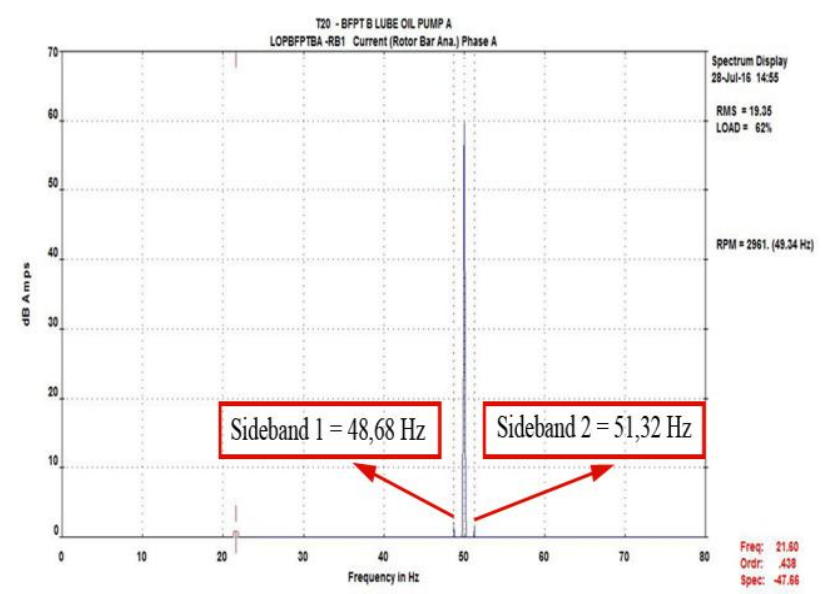

Fig. 14. Sideband frequency that appears between the line frequency

To analyze the condition of the rotor bar on an induction motor, it is necessary to first calculate the frequency of running speed of the induction motor. Based on the operation data of the induction motor, it is found that the motor rotation is $2961 \mathrm{rpm}$. Thus, the frequency of running speed of the induction motor is $49.34 \mathrm{~Hz}$. After knowing the running speed frequency of $49.34 \mathrm{~Hz}$, to find out the value of the synchronous speed frequency, which is according to the nominal frequency of $50 \mathrm{~Hz}$. By calculating the running speed and the synchronous speed or slip 
frequency, the side band frequencies that occur around the line frequency can be determined. The sideband frequency of the MCSA analysis was 1.32 Hz. Based on the sideband frequency value of 1.32 $\mathrm{Hz}$, it can be interpreted that the sideband that appears around the frequency line is $48.68 \mathrm{~Hz}$ and $51.32 \mathrm{~Hz}$. The value of the sideband frequency that appears between the line frequency can be seen in Fig. 14.

Furthermore, to determine the indication of the damage to the rotor bar of an induction motor, it can be seen the amount of decrease that occurs between the line frequency and the side band frequency. Determination of the presence or absence of rotor damage must be in accordance with the standards of EASA as shown in Fig. 10. Fig. 10 shows that if the sideband frequency that occurs is $-17.32 \mathrm{~Hz}$ at the peak of the line frequency of $50 \mathrm{~Hz}$, or if using the Fast Fourier Transform (FFT) algorithm can be converted to a value of $-40 \mathrm{~dB}$, it can be determined that the motor is identified with a damage to the rotor bar. By comparing the results of the analysis at low frequency with the standard from EASA, it can be seen that the degradation on the spectrum curve is $44.55 \mathrm{~dB}$, so it can be said that the motor lube oil bfpt pump identifies damage to the rotor bar.

The next analysis is the current imbalance in each phase of the induction motor. The measurement results show that when there is a disturbance in the induction motor, the current in the $\mathrm{R}$ phase is 20.44 amperes, the $\mathrm{S}$ phase is 21.47 amperes, and the $\mathrm{T}$ phase is 20.30 amperes. The results of the current measurement for each phase can be seen that the currents for each phase are balanced. However, to ensure the development of the rotor bar conditions, the data is processed and analyzed using AMS Suite Machinery software. Data analyzed and processed into the AMS Suite Health Machinery software is the result of measurements with $\mathrm{CSi} 2130$ which shows the flow is not balanced between the phases. If the MCSA measurement results with CSi 2130 produce normal conditions, the data will not be processed and analyzed further, but monitoring is still carried out according to a periodic checking schedule.

The results of the analysis of the percentage of unbalanced current from the induction motor on the motor lube oil bfpt pump when a disturbance occurs which is analyzed using AMS Health Machinery software is shown in Fig. 15.

From the AMS Suite Health Machinery analysis results obtained the percentage of current unbalance data is $0.3 \%$, the adjusted delta is $55.16 \mathrm{~dB}$, and the percentage of damage to the rotor bar is $0.6 \%$.

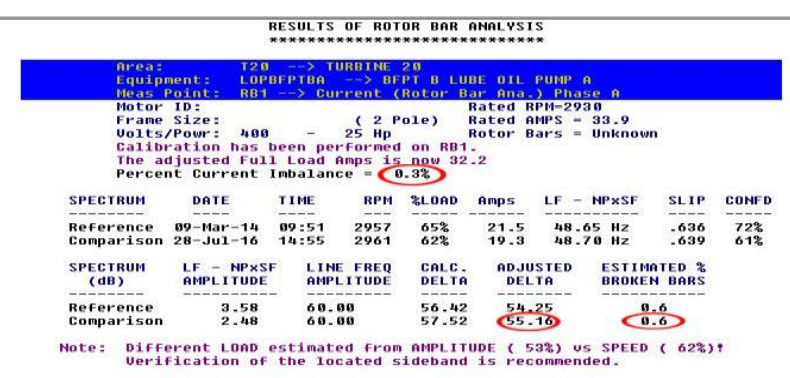

Fig. 15. Results of the analysis of the percentage of unbalanced current of the induction motor after reparation

From the results of experimental data and analysis results obtained percent unbalance flow of $0.3 \%$. The induction motor manufacturer has determined the allowable level for the percent of unbalanced current not to exceed $10 \%$. The imbalance of the current between the phases in a three-phase induction motor can affect the value of the voltage and resistance on the motor. With the greater the current value, the greater the voltage and the smaller the resistance and vice versa. If any of the $\mathrm{R}, \mathrm{S}$, and $\mathrm{T}$ phases are over current it can cause over voltage, if this happens it will cause overheating. If there is a small current in one of the phases, the possibility of resistance will be even greater, and this can also cause overheating. So that from condition-based maintenance (CBM) provides recommendations for checking the termination related to the condition of the motor temperature. In addition, the size of the resistance also affects the current and voltage so that the CBM provides a recommendation to check the winding resistance.

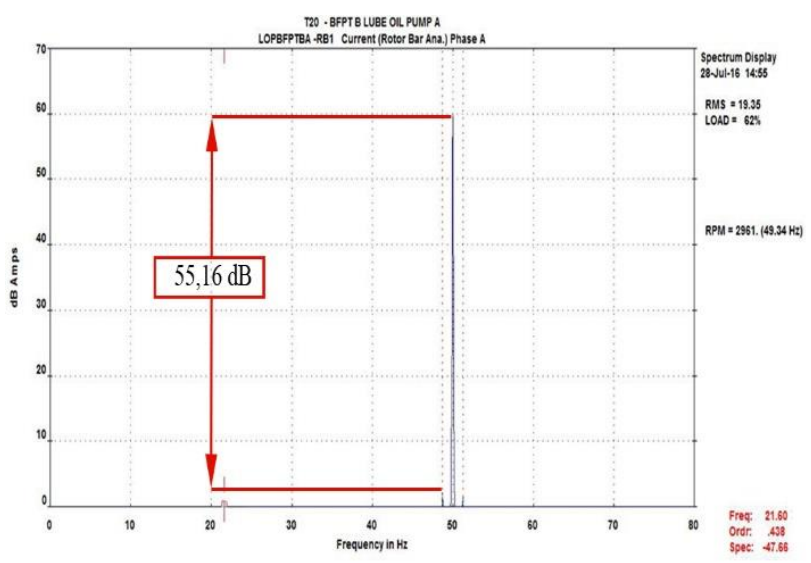

Fig. 16. A signal that indicates a damage to the rotor bar of the induction motor 
The estimate for broken rotor bars is $0.6 \%$. If the estimation is getting bigger, the condition of the rotor bar is getting worse. The condition of the rotor bar damage can be seen as shown in Fig. 16. The signal gain $(\Delta \mathrm{dB})$ is $55.16 \mathrm{~dB}$. This value is obtained from the difference between the peak frequency and the lower side band. In accordance with the standards of the Electrical Apparatus Service Association (EASA), the data shows the motor is in "normal condition".

\section{Conclusion}

Motor Current Signature Analyzer (MCSA) technology can show damaged rotor bars and unbalanced currents in 3-phase electric motors with sideband analysis around the line frequency. In the post-disturbance induction motor test, the signal gain value is $44.55 \mathrm{~dB}$. According to EASA standards, the data shows the motor is in "marginal condition". This condition indicates that the motorbike is approaching a lousy need to carry out monitoring and repair. This fact helps prevent more catastrophic losses due to system downtime. After repairing the induction motor's rotor, the results of the signal amplification analysis showed a value of $55.16 \mathrm{~dB}$. Based on the EASA standard, this value is in the "normal condition" category. This is reinforced by the fact that the current in each phase of the induction motor is balanced, with the percentage of imbalance only $0.3 \%$. Thus, the induction motor condition after the repair can be used for operation at Steam Power Plants (SPP) Rembang.

\section{References}

[1] Da Silva, A. M., (2006). Induction Motor Fault Diagnostic and Monitoring Method, Marquette University, Milwaukee, May 2006.

[2] A. Glowacz, W. Glowacz, Z. Glowacz and J. Kozik, "Early fault diagnosis of bearing and stator faults of the single-phase induction motor using acoustic signals", Measurement, vol. 113, pp. 1-9, Jan. 2018.

[3] I.H. Kao, W.J. Wang, Y.H. Lai, J.W. Perng, (2019). Analysis of Permanent Magnet Synchronous Motor Fault Diagnosis Based on Learning. IEEE Transactions on Instrumentation and Measurement, vol. 68, Issue 2, Feb. 2019, pp. 310 - 324.

[4] Huang, X., Diagnostic of Airgap Eccentricity in Closed-Loop Drive Connected Induction Motors, Georgia Institute of Technology, Mei 2005.

[5] P. Rzeszucinski, M. Orman, C. T. Pinto, A. Tkaczyk and M. Sulowicz, "Bearing health diagnosed with a mobile phone: Acoustic signal measurements can be used to test for structural faults in motors", IEEE Ind. Appl. Mag., vol. 24, no. 4, pp. 17-23, Jul. 2018.

[6] J. J. Xiao, R. Shepler, Y. Windiarto, S. Parkinson and R. Fox, "Development and field test of ESP reliable power delivery system", Proc. SPE Kingdom Saudi Arabia Annu. Tech. Symp. Exhib., pp. 1-12, 2016.

[7] M. R. W. Group, "Report of large motor reliability survey of industrial and commercial installation, PartII," IEEE Trans. Ind. Appl., vol. IA-21, no.4, pp. 865-872, July/Aug. 1985.

[8] B. Corne, J. Knockaert and J. Desmet, "Misalignment and unbalance fault severity estimation using stator current measurements", Proc. IEEE 11th Int. Symp. Diagnostics Elect. Mach. Power Electron. Drives (SDEMPED), pp. 247-253, Aug. 2017.

[9] Jose A. Antonino Daviu, Joan Pons-Llinares and Sang Bin Lee, "Advanced rotor fault assessment for high voltage induction motors via continuous transforms", Proc. Petroleum Chem. Ind. Conf. Europe, pp. 57-63, Jun. 2015.

[10] S.B. Lee, E. Wiedenbrug and K. Younsi, "ECCE 2013 tutorial: Testing and diagnostics of induction machines in an industrial environment", Sep. 2013.

[11] Penrose, H.W., Practical Motor Current Signature Analysis Taking the Mystery Out of MCSA, ALL TEST Pro, BJM Corp USA, 2003.

[12] T. Yang, H. Pen, Z. Wang, C.S. Chang, (2016). Feature Knowledge Based Fault Detection of Induction Motors Through the Analysis of Stator Current Data. IEEE Transactions on Instrumentation and Measurement, vol. 65, Issue 3, March 2016, pp. $549-558$.

[13] Menacer, A., Said, M., Stator Current Analysis of Incipient Fault into Asynchronous Motor Rotor Bar Using Fourier Fast Transform, Journal of Electrical Engineering, Vol 55, 2004.

[14] Pillay, P., Xu, Z., Motor Current Signature Analysis, IDM controls, Georgia, 1996.

[15] Y.S. Kuncara, (2013). "Analisa kerusakan rotor bar dan static eccentricity motor induksi lp drain pump beban $110 \mathrm{kw}$, 380-volt dengan metode mesa di pt. indonesia power ubp suralaya", Skripsi, Teknik Elektro, Universitas Mercu Buana, Jakarta.

[16] I.G.P. Yudiastawan, (2009). "Deteksi Kerusakan Bearing dan Eccentricity pada motor induksi tiga fasa dengan Current Signature Analysis", Tesis, Teknik Elektro, Universitas Indonesia, Jakarta.

[17] W.T. Thomson and I. Culbert, Current Signature Analysis for Condition Monitoring of Cage Induction Motors, Hoboken, NJ, USA: Wiley, 2017.

[18] B. Ayhan, Chow, M.Y., Song, M.H., Trussel, H.J, (2005). Application of Notch Filtering under Low Sampling Rate for Broken Rotor Bar Detection with DTFT and AR based Spectrum Methods, IEEE Trans on Energy Conversion, vol 20 no 2, June, 2005.

[19] N. Afrizal, R. Ferraro, (2020). Leakage Error Compensation in Motor Current Signature Analysis for Shaft Misalignment Detection in Submersible Pumps. IEEE Transactions on Instrumentation and 
Measurement, vol. 69, Issue 11, 2020, pp. 8821 8830 .

[20] S. Tomar and P. Sumathi, "Amplitude and frequency estimation of exponentially decaying sinusoids", IEEE Trans. Instrum. Meas., vol. 67, no. 1, pp. 229237, Jan. 2018.

\section{Authors' information}

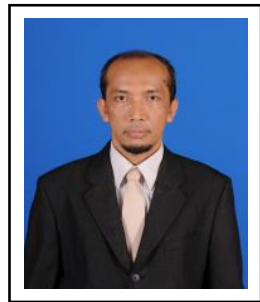

Ramadoni Syahputra received Ph.D degree at the Department of Electrical Engineering, Faculty of Industrial Technology, Institut Teknologi Sepuluh Nopember in 2015.

Dr. Ramadoni Syahputra is a Lecturer in Department of Electrical Engineering, Universitas Muhammadiyah Yogyakarta, Indonesia. His research interests are in artificial intelligence in power system, computational of power system, power system control, fuzzy logic in power system, optimization, and renewable energy.

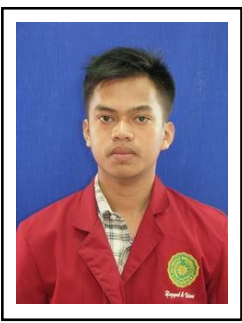

Hedi Purwanto received B.Sc. degree from Department of Electrical Engineering, Universitas Muhammadiyah Muhammadiyah Yogyakarta, Yogyakarta, Indonesia, in 2017.

His research interests are in power system operasion.

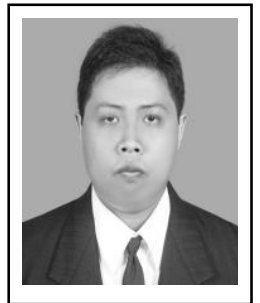

Rama Okta Wiyagi Received B.Sc degree from Department of Electrical Engineering Universitas Muhammadiyah Yogyakarta in 2009, M.Eng. degree from Department of Electrical Engineering and Informatics Technology, Universitas Gadjah Mada, Yogyakarta, Indonesia in 2014. Rama Okta Wiyagi, M.Eng. is a Lecturer in Department of Electrical Engineering, Universitas Muhammadiyah Yogyakarta, Indonesia. His research interests are in control system, computer vision, robotics, and instrumentation.

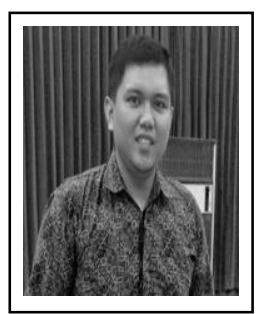

Muhamad Yusvin Mustar Received Diploma degree Electrical Engineer from Universitas Haluoleo, Kendari in 2009, B.Sc. degree from from Department of Electrical Engineering Universitas Muhammadiyah Yogyakarta in 2011, M.Eng. degree from Department of Electrical Engineering and Informatics Technology, Universitas Gadjah Mada, Yogyakarta, Indonesia in 2014

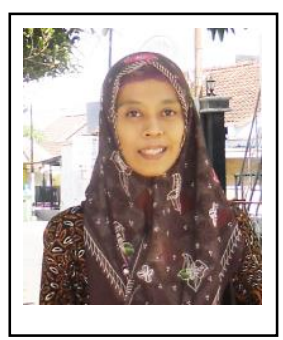

Indah Soesanti was born on June 15, 1974. She received both M.Eng. and Ph.D. degrees from Department of Electrical Engineering, Gadjah Mada University, Yogyakarta, Indonesia in 2001 and 2011, respectively.

Dr. Indah Soesanti is a Lecturer in the Department of Electrical Engineering and Information Technology, Faculty of Engineering, Universitas Gadjah Mada, Indonesia. Her research interests are in signal processing, image processing, control system, ICT-based system, optimization, artificial intelligence in signal processing pattern classification, and artificial intelligence in control system. 